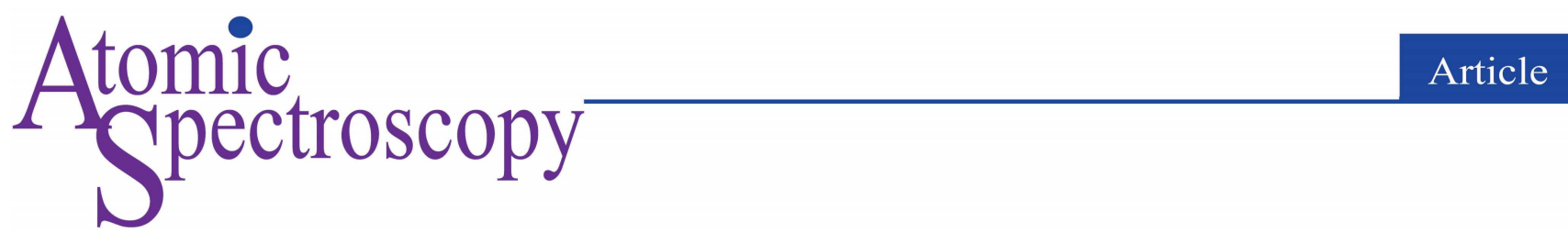

\title{
Characterization of Hafnium Metal for its Impurities by Glow Discharge Quadrupole Mass Spectrometry Using a Non-Matrix Matched Standard
}

\author{
R. Shekhar,* M. A. Reddy, S. Thangavel, Y. Sunitha, A. C. Sahayam, and Sanjiv Kumar

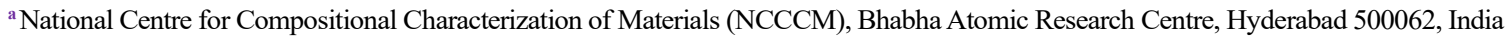

Received: May 15, 2020; Revised: Jun. 05, 2020; Accepted: Jun. 05, 2020; Published: Jun. 25, 2020.

DOI: 10.46770/AS.2020.03.002

ABSTRACT: A method for the determination of impurities in hafnium (Hf) metal by glow discharge quadrupole mass spectrometry (GD-QMS) is described. The method represents a combinatorial approach that utilizes a non-matrix matched standard, namely a Ni-based superalloy, and an internal standard element ( $\mathrm{Zr}$ ) in $\mathrm{Hf}$ for the calculation of the relative sensitivity factors (RSFs) of the elements for their quantification. The direct use of $\mathrm{Hf}$ present in the Ni superalloy for quantification is prevented due to the grossly inhomogeneous distribution of the element in the alloy standard. The concentration of the internal standard element in the Hf specimen was determined by two independent techniques: inductively coupled plasma optical emission spectrometry (ICP-OES) and X-ray fluorescence spectrometry (XRF). The isobaric interferences from the polyatomic ions of $\mathrm{Hf}$ formed in the glow discharge plasma were systematically investigated. The validation exercise that entailed the determination of a few elements in the Hf specimen by ICP-OES showed that the present approach yields reliable results and thus, is recommended for the determination of impurities that include metals as well as non-metals in $\mathrm{Hf}$

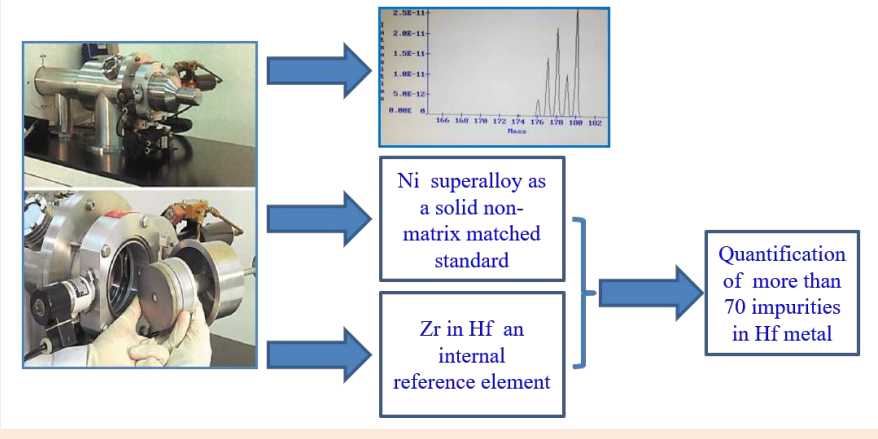
and Hf-alloys.

\section{INTRODUCTION}

Hafnium (Hf), a group IVB element, is an important nuclear material finding application primarily in the control rods of nuclear reactors by virtue of its high thermal neutron capture cross-section and excellent physical and chemical properties that include high melting point $\left(2225^{\circ} \mathrm{C}\right)$, high ductility, good machinability and hot water corrosion resistance. ${ }^{1,2} \mathrm{Hf}$ occurs in nature $(4.5 \mathrm{~g} / \mathrm{t})$ invariably with its cogenic element zirconium and has six stable isotopes. The ${ }^{177} \mathrm{Hf}$ isotope, with a fractional abundance of 0.186 , has the highest contribution $(68.8 \%, 371 \mathrm{~b})$ to the thermal neutron absorption cross-section (102 b) of the element. ${ }^{1,2}$ Incidentally, the thermal neutron absorption cross-section of $\mathrm{Zr}$ is much less, only $0.185 \mathrm{~b}$, which makes it an excellent cladding material in nuclear reactors. It is important to note that zircon is a double silicate $\mathrm{ZrSiO}_{4}$. $\mathrm{HfSiO}_{4}$, with a $\mathrm{Hf} / \mathrm{Zr}$ ratio of about 0.025 , is the main source of $\mathrm{Hf}$ and, therefore, the presence of $\mathrm{Zr}$ in larger quantities can adversely affect the neutron absorption property of Hf. The prevalence of other impurity elements can produce similar effects. The chemical composition, including the (maximum) trace impurity contents in nuclear grade $\mathrm{Hf}$ (R1 and R2), is outlined in ASTM B3737 and B776 and serves as guidelines in the production of the element for control rods. ${ }^{2}$ Importantly, high purity $\mathrm{Hf}$ can reportedly extend the service life of the water-water energetic reactor up to 60 years. ${ }^{3}$ It is instructive to mention that $\mathrm{Hf}$ is also used in spent fuel processing, essentially due to its high corrosion resistance in nitric acid and neutron capture cross-section.

Among the non-nuclear applications, $\mathrm{Hf}$ is used as an alloying element in superalloys and refractory alloys and finds application in aerospace engineering and other areas. ${ }^{4}$ It imparts superior mechanical properties and oxidation resistance to the alloys. It produces hardness either by solid solution strengthening, or by the formation of a fine dispersion of oxides, carbides or nitrides that 
results due to its affinity for these light elements. High purity hafnium, as such, is very soft, but the introduction of oxygen or nitrogen increases its hardness and tensile stress. Nuclear-grade Hf, containing 300 ppm oxygen, has mechanical properties similar to those of zircaloy. It is to be noted that as per ASTM specifications, the content of oxygen in R1 and R2 grade hafnium is about 400 and $800 \mathrm{ppm}$, respectively. In addition to alloys, hafnium is also used in the production of specialty chemicals and thin films among which $\mathrm{HfO}_{2}$ is probably the most extensively investigated high $\mathrm{k}$ dielectric material. ${ }^{5}$

The determination of impurity elements, which includes metals and non-metals, is required for quality assurance and quality control of nuclear or commercial grade hafnium in reference to ASTM B3737 and B776 specifications. Several spectrography, spectrochemical and spectroscopic methods are reported in this context. ${ }^{6}$ In fact, due to the close similarity in the chemical properties of $\mathrm{Zr}$ and $\mathrm{Hf}$, the methods for analyzing $\mathrm{Zr}$, which are more prevalent, can be utilized for the analysis of Hf. The past few decades have witnessed the growth of several sophisticated instrumental techniques endowed with good sensitivity for a large number of elements and / or simultaneous multielement detection capability and, therefore, are potentially well suited for determining impurities in $\mathrm{Hf}^{7}$ ICP-OES, inductively coupled plasma mass spectrometry (ICP-MS) and graphite furnace atomic absorption spectrometry (GF-AAS) are among the most important examples of such techniques. ICP-OES and ICP-MS provide the simultaneous determination of a number of elements down to parts per million (ppm) and parts per billion ( $\mathrm{ppb}$ ) level, respectively. GF-AAS displays high sensitivity for several elements but is mono-elemental and, therefore, the determination of several elements can be time-consuming. Importantly, these three techniques are solution-based techniques, and therefore are not suitable for measuring low $\mathrm{Z}$ non-metallic elements such as carbon, nitrogen or oxygen. These facts notwithstanding, none of these techniques has hitherto been used for the analysis of Hf.

Glow discharge mass spectrometry (GDMS) is yet another important instrumental analytical technique. Features such as solid sample analysis, simultaneous multielement detection capability, similar sensitivity to low and high $\mathrm{Z}$ elements, and their determination from percentage to ultratrace levels in a single run makes GDMS a powerful and versatile technique. ${ }^{8}$ Literature is replete with instances wherein this technique has been used for the analysis of metals, alloys, semiconductors and several other matrices. ${ }^{9-12}$ However except the study by Quin et al. ${ }^{13}$ there is no other report on the analysis of Hf metal by GDMS in open literature. Quin et al determined the impurities in Hf granules measuring $2 \mathrm{~mm} \times 1 \mathrm{~mm} \times 1 \mathrm{~mm}$ in dimension and grafting them with indium. The analysis, though novel in approach, was semiquantitative.

The lack of a comprehensive quantitative study prompted us to undertake the present work wherein we have utilized GD-QMS for the analysis of Hf metal sheets and validated the analytical results by ICP-OES. One of the important features of the study is the development of a methodology that utilizes a non-matrix matched standard and an internal reference element for the quantification of more than 70 elements, which includes carbon, nitrogen and oxygen as well. A systematic study of the isobaric interferences for an unambiguous qualitative and quantitative analysis has also been performed. Good analytical figures of merit and validation of the results point to the robustness of the methodology.

\section{EXPERIMENTAL}

Analysis by GD-QMS. A quadrupole GD-QMS (VG Elemental, U.K., Model: GQ230), located in the Class 100 clean room (ISOClass-5) of the Ultra Trace Analysis Laboratory of the Centre, was used for the present work. The glow discharge was generated and operated in constant current mode, where the discharge voltage was adjusted by changing the flow rate of argon gas using a gas inlet valve. The discharge gas was argon of $99.999 \%$ purity, which was additionally purified by an on-line active metal getter. The system interlock gate was operated using compressed argon gas (65 psi) of $99.995 \%$ purity. The dual detector system (Model No. 4870V, BURLE Electro-Optics Inc., USA) utilizes an electron multiplier for ion counting of the trace elements (ion currents < $1 \times 10^{-13}$ Amp) and a Faraday cup for measuring the major and minor elements (ion currents $>1 \times 10^{-13} \mathrm{Amp}$ ). The detector system provides a dynamic linear range of more than eight orders of magnitude. Control of the instrument and data acquisition were handled by Glo-Quad software. The peak jump mode was used for data acquisition. A 10-mm diameter anode opening flat sample holder was used. A nickel-based superalloy disc, containing the majority of elements ranging from carbon to tungsten, was used for mass calibration of the instrument over the entire mass range. Calibration of both detectors (Faraday and electron multipliers) was done on a day-to-day basis. Faraday cup and electron multiplier detectors were cross-calibrated by measuring the signal intensity at mass $80\left({ }^{40} \mathrm{Ar}_{2}{ }^{+}\right)$by keeping the appropriate discharge current to avoid saturation of the electron multiplier. The detector calibration factor was set to $2520 \pm 200$ by adjusting the HT voltage to the electron multiplier before scanning. Detector calibration and analytical measurements were carried out with a mass step of $0.01 \mathrm{amu}$ and 120 number of data points per peak.

Sample preparation and measurement details. The Hf metal was cleaned with iso-propanol, dried under an IR lamp, and subsequently placed into the GD-QMS system using a flat sample holder with an anode opening diameter (sputtering area of the sample) of $10 \mathrm{~mm}$. Two Teflon spacers (each of $0.5 \mathrm{~mm}$ thickness) with inner diameters of $15 \mathrm{~mm}$ (towards the sample) and $20 \mathrm{~mm}$ (towards anode) were placed between anode and sample, which served as insulators between the glow discharge anode and 
Table 1 GD-QMS Instrumental Parameters

\begin{tabular}{|c|c|}
\hline Parameter & Value \\
\hline Discharge voltage $(\mathrm{kV})$ & 1.0 \\
\hline Discharge current (mA) & 3.0 \\
\hline Argon gas flow rate $\left(\mathrm{mL} \mathrm{min}^{-1}\right)$ & 29 \\
\hline Vacuum (quadrupole region) (mbar) & $1.0 \times 10^{-6}$ \\
\hline Resolution (M/ $\mathbf{\Delta M})$ & 300 \\
\hline Isotopes used for quantification & $\begin{array}{l}{ }^{7} \mathrm{Li},{ }^{9} \mathrm{Be},{ }^{11} \mathrm{~B},{ }^{12} \mathrm{C},{ }^{14} \mathrm{~N},{ }^{16} \mathrm{O},{ }^{23} \mathrm{Na},{ }^{24} \mathrm{Mg},{ }^{27} \mathrm{Al},{ }^{30} \mathrm{Si},{ }^{31} \mathrm{P},{ }^{34} \mathrm{~S},{ }^{35} \mathrm{Cl},{ }^{44} \mathrm{Ca},{ }^{45} \mathrm{Sc},{ }^{48} \mathrm{Ti},{ }^{51} \mathrm{~V},{ }^{52} \mathrm{Cr},{ }^{55} \mathrm{Mn} \text {, } \\
{ }^{56} \mathrm{Fe},{ }^{58} \mathrm{Ni},{ }^{59} \mathrm{Co},{ }^{63} \mathrm{Cu},{ }^{66} \mathrm{Zn},{ }^{70} \mathrm{Ge},{ }^{71} \mathrm{Ga},{ }^{75} \mathrm{As},{ }^{79} \mathrm{Br},{ }^{82} \mathrm{Se},{ }^{85} \mathrm{Rb},{ }^{86} \mathrm{Sr},{ }^{89} \mathrm{Y},{ }^{91} \mathrm{Zr},{ }^{93} \mathrm{Nb},{ }^{98} \mathrm{Mo},{ }^{102} \mathrm{Ru}, \\
{ }^{103} \mathrm{Rh},{ }^{108} \mathrm{Pd},{ }^{109} \mathrm{Ag},{ }^{114} \mathrm{Cd},{ }^{115} \mathrm{In},{ }^{118} \mathrm{Sn},{ }^{121} \mathrm{Sb},{ }^{127} \mathrm{I},{ }^{128} \mathrm{Te},{ }^{133} \mathrm{Cs},{ }^{138} \mathrm{Ba},{ }^{139} \mathrm{La},{ }^{140} \mathrm{Ce},{ }^{141} \mathrm{Pr},{ }^{142} \mathrm{Nd}, \\
{ }^{152} \mathrm{Sm},{ }^{153} \mathrm{Eu},{ }^{158} \mathrm{Gd},{ }^{159} \mathrm{~Tb},{ }^{164} \mathrm{Dy},{ }^{165} \mathrm{Ho},{ }^{166} \mathrm{Er},{ }^{169} \mathrm{Tm},{ }^{175} \mathrm{Lu},{ }^{180} \mathrm{He},{ }^{181} \mathrm{Ta},{ }^{186} \mathrm{~W},{ }^{187} \mathrm{Re},{ }^{189} \mathrm{Os},{ }^{119} \mathrm{Ir}, \\
{ }^{198} \mathrm{Pt},{ }^{197} \mathrm{Au},{ }^{202} \mathrm{Hg},{ }^{205} \mathrm{Tl},{ }^{208} \mathrm{~Pb}, \text { and d }{ }^{209} \mathrm{Bi} .\end{array}$ \\
\hline
\end{tabular}

cathode. The sample was kept under vacuum (better than $1 \times 10^{-3}$ mbar) inside the GD-QMS system for about two minutes prior to striking the plasma to remove the atmospheric surface contaminants. The discharge parameters were optimized in constant current mode to obtain maximum counts per second for ${ }^{180} \mathrm{Hf}^{+}$ion. The optimized discharge conditions of the GD-QMS for the maximum hafnium matrix signal are listed in Table 1. The surface of the sample was etched in GD plasma at a discharge voltage of $1.0 \mathrm{kV}$ and discharge current of $3 \mathrm{~mA}$ for $50 \mathrm{~min}$ in order to eliminate the embedded surface contaminants, such as $\mathrm{C}$, $\mathrm{N}, \mathrm{O}$ and hydrocarbon materials. The Faraday detector with a single scan for the matrix element (Hf) and the electron multiplier with 20 scans for each impurity isotope was used for scanning all constituent and impurity elements. Five repetitive measurements were recorded for all isotopes.

Determination of impurities by ICP-OES. Hf metal ( $0.2 \mathrm{~g})$ was dissolved in a Teflon beaker containing $3 \mathrm{~mL}$ ultrapure water, followed by dropwise addition of $0.5 \mathrm{~mL} \mathrm{HF}(48 \%$, w/v) and $2 \mathrm{~mL}$ sub-boiled $\mathrm{HNO}_{3}$. The sample solution was diluted to $250 \mathrm{~mL}$ in a Teflon/HDPE standard flask using ultrapure water. The sample solution was passed into an inductively coupled plasma optical emission spectrometer (Horiba Jobin Yvon JY-Ultima II, France) for the determination of $\mathrm{Mg}, \mathrm{Al}, \mathrm{Cr}, \mathrm{Fe}$ and $\mathrm{Zr}$. These elements were determined in the Hf metal by external calibration using standard solutions prepared by appropriate dilution of the standard stock solutions ( $1 \mathrm{mg} \mathrm{mL}{ }^{-1}$ CertiPUR, E-Merck, Germany). Hf has several emission spectral lines which can interfere in the determination of impurities in a $\mathrm{Hf}$ matrix. The spectral interference due to Hf was studied by measuring the analytical signal at the respective analytical wavelengths of all analytes using a $0.8 \mathrm{mg} \mathrm{mL}^{-1} \mathrm{Hf}$ standard solution.

Determination of $\mathbf{Z r}$ by XRF. The XRF measurements were performed using the Spectro Xepos spectrometer (Spectro Scientific, USA). Molybdenum K $\alpha$ X-rays were used as the excitation source. For all measurements, the X-ray source was operated at $35 \mathrm{KV}$ and $20 \mathrm{~mA}$. The spectrometer has a Si-PIN detector with an energy resolution of $125 \mathrm{eV}$. The concentration of $\mathrm{Zr}$ in Hf was determined by a fundamental parameter model.

\section{RESULTS AND DISCUSSION}

The analysis of a sample by GDMS consists of the following three major steps: (a) sputtering of the sample by the plasma ions in the glow discharge, (b) ionization of the sputtered neutral atoms, and (c) mass analysis by a mass spectrometer, presently a quadrupole mass spectrometer, and measurement of the ion currents of the ion species. Quantification of the elements in the sample is accomplished by invoking the concept of the relative sensitivity factor (RSF), defined by the following expression:

$$
\left(\frac{C_{x}}{C_{s}}\right)=R S F(x / s) \times\left(\frac{I_{x}}{I_{s}}\right)
$$

where $\mathrm{C}$ represents the concentration, I the ion current, and the subscripts $\mathrm{x}$ and $\mathrm{s}$ represent the analyte and the matrix, respectively. ${ }^{12,14}$ This formulation is based on the fact that the ratio of the currents (i.e., ion beam ratio or IBR) of two ions is directly proportional to the ratio of their respective concentrations. The process of quantification essentially involves (i) the determination of the RSFs of the elements in a standard, (ii) their multiplication, as shown in the equation (1), to the measured ion ratios in the samples to determine the respective relative concentrations, and (iii) the calculation of the concentration of the individual elements including the matrix element (s) by normalizing the total measured relative concentrations to $100 \%$. The standard should preferably be matrix-matched, i.e. its chemical composition should be similar to that of the sample. However, the RSF has been reported to be largely independent of the matrix, which is attributed to the nonselective sputtering of the atoms and a 'disconnect' between the processes of sputtering and ionization. ${ }^{15,16}$ Thus, non-matrix matched standards can also be used for quantification without introducing significant errors. ${ }^{17-19}$

Since a matrix-matched solid reference material (RM) for $\mathrm{Hf}$ metal was also not available, a nickel-based superalloy (CM247LC, Cannon-Muskegon Corporation, USA) was utilized as the non-matrix matched internal standard material. The concentrations of the constituent elements of the alloy were determined and certified by the supplier and are listed in Table 2. The selection of the superalloy is based on the fact that it was the only standard available to us that contains Hf. 
Table 2 Concentration of the Constituents and Impurities in Ni-based Superalloy Internal Standard and RSF Values with RSDs (n=4)

\begin{tabular}{|c|c|c|c|c|c|c|c|}
\hline Element & $\begin{array}{c}\text { Concentration } \\
\left(\mu \mathrm{g} \mathrm{g}^{-1}\right) \\
\end{array}$ & RSF & $\%$ RSD & Element & $\begin{array}{c}\text { Concentration } \\
\left(\mu \mathrm{g} \mathrm{g}^{-1}\right) \\
\end{array}$ & RSF & $\%$ RSD \\
\hline $\mathbf{L i}$ & $<0.1$ & 0.0014 & 10 & $\mathbf{R h}$ & $<0.3$ & 0.0733 & 10 \\
\hline Be & $<0.3$ & 0.1776 & 11 & Pd & $<0.3$ & 0.0618 & 14 \\
\hline B & 150 & 0.5073 & 5 & Ag & $<0.5$ & 0.2585 & 9 \\
\hline C & 720 & 1.0962 & 5 & Cd & $<0.5$ & 0.1057 & 10 \\
\hline $\mathbf{N}$ & 1.0 & 0.0000033 & 6 & In & $<0.1$ & 0.0645 & 12 \\
\hline $\mathbf{O}$ & 1.0 & 0.0090 & 12 & Sn & 3.0 & 0.1460 & 10 \\
\hline $\mathbf{N a}$ & $<20$ & 0.0008 & 2 & Sb & 0.2 & 0.1717 & 12 \\
\hline Mg & $<75$ & 0.2216 & 4 & I & $<0.1$ & 0.1099 & 13 \\
\hline Al & 56200 & 0.2798 & 3 & Te & 0.1 & 0.0385 & 6 \\
\hline $\mathbf{S i}$ & 100 & 0.0248 & 4 & Cs & $<0.3$ & 0.4367 & 9 \\
\hline $\mathbf{P}$ & 50 & 1.1338 & 3 & $\mathbf{B a}$ & $<0.1$ & 0.0397 & 5 \\
\hline $\mathbf{S}$ & 3 & 0.0445 & 12 & $\mathbf{L a}$ & $<0.1$ & 0.1942 & 14 \\
\hline Cl & 0.7 & 0.0013 & 11 & $\mathrm{Ce}$ & $<0.1$ & 0.1455 & 14 \\
\hline $\mathrm{Ca}$ & 1.0 & 0.0001 & 11 & Pr & $<0.1$ & 0.2464 & 15 \\
\hline Sc & $<0.1$ & 0.0018 & 9 & Nd & $<0.3$ & 0.2438 & 14 \\
\hline $\mathbf{T i}$ & 7000 & 0.0063 & 15 & Sm & $<0.3$ & 0.2634 & 15 \\
\hline $\mathbf{V}$ & 5.0 & 0.2362 & 10 & $\mathbf{E u}$ & $<0.3$ & 0.3848 & 13 \\
\hline $\mathrm{Cr}$ & 82000 & 0.6877 & 12 & Gd & $<0.3$ & 0.2977 & 15 \\
\hline Mn & 10 & 0.1040 & 15 & $\mathbf{T b}$ & $<0.3$ & 0.7022 & 15 \\
\hline $\mathrm{Fe}$ & 330 & 0.2232 & 13 & Dy & $<0.3$ & 0.3606 & 13 \\
\hline $\mathbf{N i}$ & 617020 & 1.0000 & 3 & Но & $<0.3$ & 1.0767 & 14 \\
\hline Co & 95000 & 0.6221 & 2 & $\mathbf{E r}$ & $<0.3$ & 0.4344 & 15 \\
\hline $\mathrm{Cu}$ & 10 & 0.0168 & 15 & $\mathbf{T m}$ & $<0.3$ & 0.5491 & 15 \\
\hline $\mathbf{Z n}$ & 2.0 & 0.1678 & 11 & $\mathbf{L u}$ & $<0.3$ & 0.9504 & 12 \\
\hline $\mathbf{G a}$ & 5.0 & 0.3607 & 4 & Hf & 14000 & $2.4310^{\mathrm{a}} / 1.1815^{\mathrm{b}}$ & $60 / 4$ \\
\hline Ge & $<0.3$ & 0.0087 & 7 & $\mathbf{T a}$ & 32800 & 7.4552 & 32 \\
\hline As & $<1.0$ & 0.0580 & 3 & $\mathbf{W}$ & 94000 & 5.8345 & 31 \\
\hline $\mathrm{Br}$ & $<0.3$ & 0.0883 & 7 & $\operatorname{Re}$ & $<1.0$ & 0.1791 & 15 \\
\hline Se & $<0.3$ & 0.0273 & 3 & Os & $<0.3$ & 0.1124 & 9 \\
\hline $\mathbf{R b}$ & $<0.3$ & 0.0130 & 6 & $\mathbf{I r}$ & $<0.3$ & 0.0576 & 9 \\
\hline $\mathrm{Sr}$ & $<0.3$ & 0.0023 & 4 & Pt & $<0.3$ & 0.0223 & 9 \\
\hline $\mathbf{Y}$ & $<0.5$ & 0.0631 & 5 & Au & $<0.3$ & 0.0118 & 14 \\
\hline $\mathbf{Z r}$ & 90 & 0.4052 & 4 & Hg & $<0.3$ & 0.1237 & 15 \\
\hline $\mathbf{N b}$ & 1000 & 0.7381 & 6 & Tl & $<0.1$ & 0.3008 & 15 \\
\hline Mo & 5000 & 0.8155 & 10 & $\mathbf{P b}$ & $<0.1$ & 0.1313 & 8 \\
\hline $\mathbf{R u}$ & $<0.3$ & 0.0034 & 6 & $\mathbf{B i}$ & $<0.1$ & 0.1869 & 11 \\
\hline
\end{tabular}

${ }^{\mathrm{a}}$ Uncorrected RSF, ${ }^{\mathrm{b}}$ Corrected RSF.

The RSF values of the elements, including Hf, were determined by analyzing the superalloy. The values were calculated by substituting the certified concentrations of the elements, i.e. $\mathrm{C}_{\mathrm{x}}$ and $\mathrm{C}_{\mathrm{S}}$ in the superalloy, and the inverse of the corresponding ion beam signal ratios (IBRs, i.e. $\left.\mathrm{I}_{\mathrm{x}} / \mathrm{I}_{\mathrm{s}}\right)$ obtained from multiple $(\mathrm{N}=4)$ measurements of the standard using the following equation:

$$
R S F(x / s)=\left(\frac{C_{x}}{C_{s}}\right) \times\left(\frac{I_{s}}{I_{x}}\right)
$$

The (mean) RSF values of the elements thus determined and their relative standard deviations (RSDs) of the elements in the standard alloy are listed in Table 2. An examination of the table shows that the RSF of Hf has a large RSD ( $60 \%)$ (i.e. $2.4310 \pm 1.4580)$, while the RSFs of other elements are consistent within 5-15\%. The variation in the RSF value results from the variation in the measured ion signal $\left(\mathrm{I}_{\mathrm{x}}\right.$ or $\left.\mathrm{I}_{\mathrm{s}}\right)$. Thus, the large RSD for $\mathrm{Hf}$ is indicative of a significant inhomogeneous distribution of the 
element across the depth in the alloy.

The concentration of the impurities in a sample are calculated by normalizing the values determined by equation (1) to $100 \%$. Presently, the application of this approach, where the IBRs of the elements obtained from the measurements on the Hf sample and their respective RSF values listed in Table 2 were used for calculation, did not yield consistent results. It was observed that the concentrations of the elements were marked by an unusually large RSD, which was as high as $60 \%$ for the replicate measurements. For example, the concentration of aluminum ranged from 10 to $40 \mu \mathrm{g} \mathrm{g}^{-1}$, while that of $\mathrm{Zr}$ varied from 1200 to $4800 \mu \mathrm{g} \mathrm{g}^{-1}$. These results obviously do not conform to the RSDs of the RSFs of the respective elements in the standard (Table 2) and, at the first instance, point to the rather inhomogeneous nature of the Hf sample. However, this speculation is discounted on the basis of the fact that the RSDs of the ion beam ratios of the impurity elements and Hf were constant within $10 \%$ in all three measurements. Such an unusual result has, in fact, its origin in the inhomogeneous distribution of Hf in the alloy internal standard which, as discussed earlier, gives rise to an inconsistent RSF value for the element (Table 2). Since hafnium is the matrix element of the sample, even a small uncertainty in the RSF of Hf can lead to a considerable scatter in the concentrations of all the impurity elements. Apparently, the RSF of Hf in the Ni superalloy must be accurately known for its utilization as a standard material for the determination of impurities in the Hf metal.

In order to determine the RSF of Hf in the Ni superalloy standard accurately, a simple alternative approach was devised which requires the concentration of an impurity element in the $\mathrm{Hf}$ sample to be known a priori. The impurity element should preferably be present in relatively higher concentration. Such an impurity element can be termed as an internal reference element. In this approach, the RSF of Hf, which yields the true concentration of the internal reference element in the sample, corresponds to the actual RSF value of Hf in the superalloy. Presently, $\mathrm{Zr}$ is chosen as the internal reference element. The choice is based on the observation, following an inspection of the IBR values, that the Hf sample contains $\mathrm{Zr}$ in appreciably high, probably highest concentration. This observation is in conformity with the fact that $\mathrm{Zr}$ is the most prevalent impurity in $\mathrm{Hf}$ as the latter is extracted and separated from zircon. Accordingly, the concentration of $\mathrm{Zr}$ in the Hf specimen was determined by XRF and ICP-OES. The two techniques yielded fairly consistent concentrations with the values being $3950 \pm 40 \mu \mathrm{g} \mathrm{g}^{-1}$ and $3936 \pm$ $157 \mu \mathrm{g} \mathrm{g}^{-1}$, respectively. The average value $\left(3942 \mu \mathrm{g} \mathrm{g}^{-1}\right)$ of $\mathrm{Zr}$ was taken as the true value of $\mathrm{Zr}$ in the Hf sample.

Subsequently, the RSF of Hf was varied to yield a concentration of $3942 \mu \mathrm{g} \mathrm{g}^{-1}$ of $\mathrm{Zr}$ in the Hf sample, with the normalization of the values determined by equation (1) to $100 \%$. The corresponding RSF of Hf, i.e. $1.1815 \pm 0.0472$, is listed in Table 2 and, as discussed earlier, was taken as the accurate value of the element.
Table 3 Results of the Impurities in Hafnium Metal $\left(\mu \mathrm{g} \mathrm{g}^{-1}, \mathrm{n}=4\right)$

\begin{tabular}{|c|c|c|c|c|c|}
\hline Element & Value $( \pm$ SD) & Element & Value $( \pm$ SD) & Element & Value $( \pm$ SD) \\
\hline $\mathbf{L i}$ & $0.002 \pm 0.001$ & $\mathbf{G a}$ & $0.45 \pm 0.04$ & $\mathrm{Ce}$ & $0.008 \pm 0.002$ \\
\hline $\mathrm{Be}$ & $0.073 \pm 0.007$ & Ge & $0.019 \pm 0.004$ & Pr & $0.013 \pm 0.004$ \\
\hline B & $0.39 \pm 0.06$ & As & $0.093 \pm 0.014$ & Nd & $0.049 \pm 0.011$ \\
\hline C & $79 \pm 21$ & $\mathrm{Br}$ & $0.048 \pm 0.009$ & Sm & $0.050 \pm 0.005$ \\
\hline $\mathbf{N}$ & $0.021 \pm 0.005$ & Se & $0.052 \pm 0.011$ & Eu & $0.037 \pm 0.008$ \\
\hline $\mathbf{O}$ & $0.21 \pm 0.04$ & $\mathbf{R b}$ & $0.009 \pm 0.001$ & Gd & $0.057 \pm 0.013$ \\
\hline $\mathrm{Na}$ & $6.0 \pm 0.5$ & $\mathrm{Sr}$ & $0.040 \pm 0.004$ & $\mathbf{T b}$ & $0.065 \pm 0.012$ \\
\hline Mg & $11 \pm 2$ & $\mathbf{Y}^{*}$ & $1.86 \pm 0.24$ & Dy & $0.069 \pm 0.026$ \\
\hline Al & $32 \pm 3$ & $\mathbf{Z r}$ & $3943 \pm 410$ & Ho & $0.057 \pm 0.012$ \\
\hline $\mathbf{S i}$ & $5.0 \pm 0.5$ & $\mathbf{N b}$ & $4.1 \pm 0.5$ & $\mathbf{E r}$ & $0.058 \pm 0.010$ \\
\hline $\mathbf{P}$ & $5.3 \pm 0.7$ & Mo & $0.82 \pm 0.16$ & Tm & $0.044 \pm 0.010$ \\
\hline $\mathbf{S}$ & $1.1 \pm 0.1$ & $\mathbf{R u}$ & $0.002 \pm 0.001$ & Lu & $0.056 \pm 0.013$ \\
\hline Cl & $0.010 \pm 0.002$ & $\mathbf{R h}$ & $0.008 \pm 0.002$ & Hf & $99.62 \pm 0.06 \%$ \\
\hline $\mathrm{Ca}$ & $0.19 \pm 0.02$ & Pd & $0.062 \pm 0.007$ & Ta & $7.3 \pm 0.9$ \\
\hline Sc & $0.029 \pm 0.003$ & Ag & $0.11 \pm 0.01$ & $\mathbf{W}$ & $1.80 \pm 0.31$ \\
\hline $\mathbf{T i}$ & $0.60 \pm 0.06$ & Cd & $0.030 \pm 0.002$ & $\operatorname{Re}$ & $0.013 \pm 0.002$ \\
\hline $\mathbf{v}$ & $0.42 \pm 0.04$ & In & $0.014 \pm 0.002$ & Os & $0.19 \pm 0.02$ \\
\hline $\mathrm{Cr}$ & $21 \pm 4$ & Sn & $0.052 \pm 0.010$ & $\mathbf{I r}$ & $0.30 \pm 0.03$ \\
\hline Mn & $0.86 \pm 0.09$ & $\mathbf{S b}$ & $0.027 \pm 0.004$ & Pt & $0.50 \pm 0.05$ \\
\hline $\mathbf{F e}$ & $17 \pm 3$ & $\mathbf{I}$ & $0.014 \pm 0.002$ & Au & $0.11 \pm 0.01$ \\
\hline $\mathbf{N i}$ & $16 \pm 3$ & $\mathbf{T e}$ & $0.010 \pm 0.002$ & Hg & $0.020 \pm 0.004$ \\
\hline Co & $1.6 \pm 0.2$ & Cs & $0.038 \pm 0.007$ & TI & $0.023 \pm 0.006$ \\
\hline $\mathrm{Cu}$ & $0.041 \pm 0.005$ & $\mathbf{B a}$ & $0.006 \pm 0.001$ & $\mathbf{P b}$ & $0.022 \pm 0.007$ \\
\hline Zn & $0.21 \pm 0.02$ & $\mathbf{L a}$ & $0.012 \pm 0.003$ & $\mathbf{B i}$ & $0.48 \pm 0.10$ \\
\hline
\end{tabular}

It was further utilized for quantification using the procedure described previously, i.e., by means of equation (1). The GD-QMS concentrations of $\mathrm{Hf}$ and the impurity elements thus determined are listed in Table 3. The values are, in fact, the mean of four independent measurements. The table also lists the standard deviation values of the measurements. The precision expressed as the percentage relative standard deviation (\%RSD) of the measurements were computed from the table and found to range from $10-20 \%$ for all elements. Notably, as the measurements were performed on four different 'aliquots', the precision can also be viewed as an indicator for the homogeneity of the sample. Incidentally, the precision of the measurements is similar to that reported in the literature. ${ }^{20}$ That is, the precision (\% RSD) reported by Jakubowski et al. for the analysis of steel alloys using GDQMS is also $10-20 \% .^{20}$

Spectral interferences. In GD-MS analysis, isobaric interferences can occur from the ions prevailing in the plasma. These ions can have their origin in the major elements constituting the matrix and or discharge gas (argon) and the atmospheric gases. The different mono- and polyatomic ions of $\mathrm{Hf}$ are identified and 

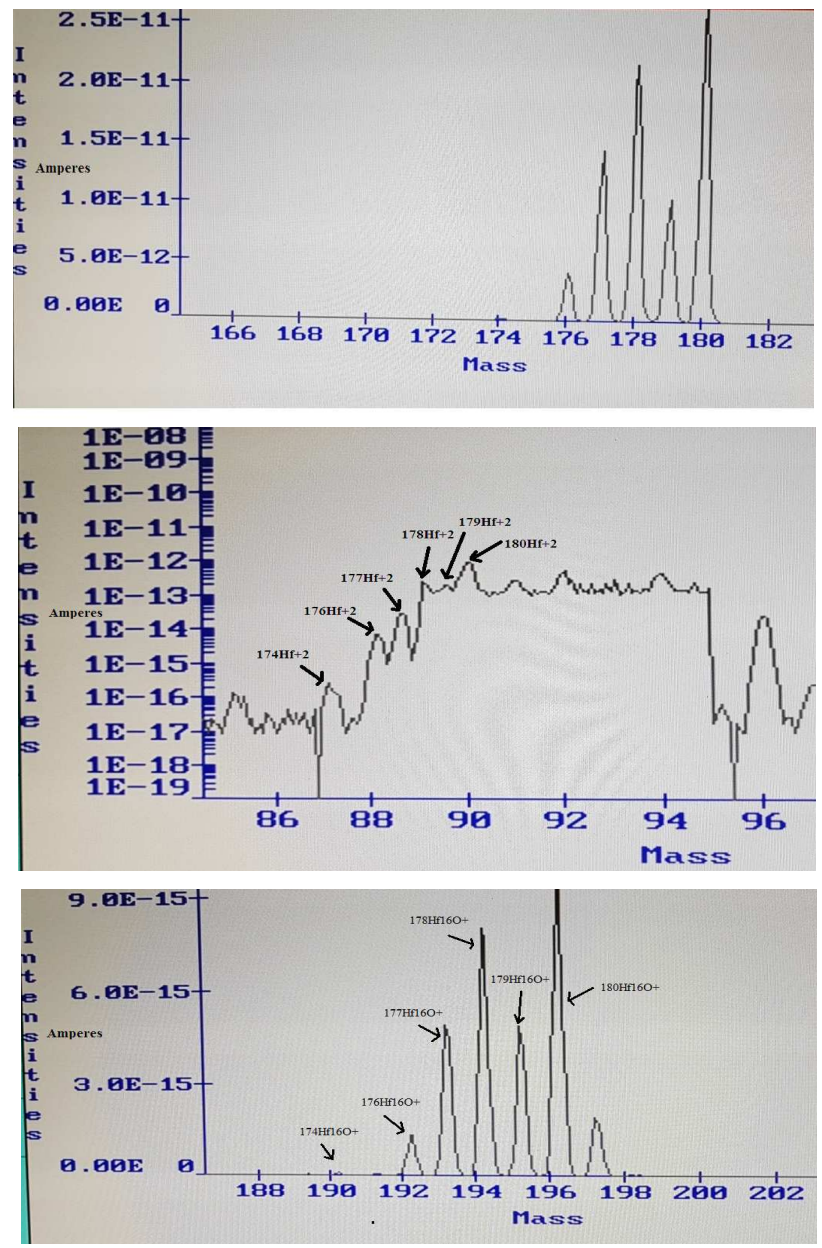

Fig. 1 Mono- and polyatomic ions observed in glow discharge plasma for Hf metal analysis: (a) All isotopes of Hf, (b) Doubly charged ions of all Hf isotopes, (c) Oxide ions of all $\mathrm{Hf}$ isotopes.

are shown in Fig. 1 for illustration. Fig. 1a consists of six wellresolved peaks which are attributed to the (six) naturally abundant stable isotopes of hafnium, namely ${ }^{174} \mathrm{Hf}(0.162),{ }^{176} \mathrm{Hf}(5.206)$, ${ }^{177} \mathrm{Hf}$ (18.606), ${ }^{178} \mathrm{Hf}$ (27.297), ${ }^{179} \mathrm{Hf}$ (13.629) and ${ }^{180} \mathrm{Hf}$ (35.10). Significantly, the relative intensities of the peaks are in accordance with their relative natural abundances (indicated in brackets), suggesting that the sample is not enriched with any particular isotope. The peaks at masses 87, 88, 88.5, 89, 89.5 and 90 in Fig. $1 \mathrm{~b}$, on the other hand, are attributable to ${ }^{174} \mathrm{Hf}^{2+},{ }^{176} \mathrm{Hf}^{2+},{ }^{177} \mathrm{Hf}^{2+}$, ${ }^{178} \mathrm{Hf}^{2+},{ }^{179} \mathrm{Hf}^{2+}$ and ${ }^{180} \mathrm{Hf}^{2+}$, respectively. As can be observed, the peaks of some of the doubly positively charged ions of $\mathrm{Hf}$ are situated on high background, while a few are on low background. The significant variation in the background across the mass spectrum arises due to the fact that the ions with $\mathrm{m} / \mathrm{z}$ from 89 to 95 were measured by the Faraday cup, while the ions with other $\mathrm{m} / \mathrm{z}$ values were measured by the electron multiplier. It is worth mentioning that the background of the Faraday signal is $1 \times 10^{-13}$ amp, whereas that of the electron multiplier signal at $1 \times 10^{-17} \mathrm{amp}$ is much lower. The difference necessitated the plotting of the spectra in log scale shown in Fig. 1b, wherein the peaks are apparently not as distinct as those of the monoatomic ions in Fig.1a, which were measured only by the Faraday cup. As a matter of fact, the peaks corresponding to the doubly positively charged $\mathrm{Hf}$ ions have good $\mathrm{S} / \mathrm{N}$ ratio and are clearly separated in linear scale. Notably, as can be seen from Fig. 1c, the peaks due to the oxide ions of the six isotopes of $\mathrm{Hf}\left(\right.$ e.g. ${ }^{178} \mathrm{Hf}^{16} \mathrm{O}^{+}$and $\left.{ }^{178} \mathrm{Hf}{ }^{16} \mathrm{O}^{+}\right)$also have a good $\mathrm{S} / \mathrm{N}$ ratio, are distinct, and bear close resemblance to monoatomic ions as shown in Fig. 1a.

The doubly positively charged Hf ions can cause interferences in the determination of strontium $(87,88)$, yttrium (89) and zirconium (90) at these masses. Yet another source of interference, particularly in the determination of platinum group metals, such as osmium $\left({ }^{190} \mathrm{Os}^{+},{ }^{192} \mathrm{Os}^{+}\right)$, iridium $\left({ }^{193} \mathrm{Ir}^{+}\right)$and platinum $\left({ }^{190} \mathrm{Pt}^{+},{ }^{192} \mathrm{Pt}^{+}\right.$, $\left.{ }^{194} \mathrm{Pt}^{+},{ }^{195} \mathrm{Pt}^{+},{ }^{196} \mathrm{Pt}^{+}\right)$, are the oxide ions of hafnium isotopes, namely ${ }^{174} \mathrm{Hf}^{16} \mathrm{O}^{+},{ }^{176} \mathrm{Hf}^{16} \mathrm{O}^{+},{ }^{177} \mathrm{Hf}^{16} \mathrm{O}^{+},{ }^{178} \mathrm{Hf}^{16} \mathrm{O}^{+},{ }^{179} \mathrm{Hf}^{16} \mathrm{O}^{+}$, ${ }^{180} \mathrm{Hf}^{16} \mathrm{O}^{+}$of masses 190, 192, 193, 194, 195, 196, respectively. Taking cognizance of these interferences, the determination of all elements, except yttrium, was performed using alternate or interference-free isotopes as listed in Table 1. As far as yttrium is concerned, it is a monoisotopic element and ${ }^{89} \mathrm{Y}^{+}$is interfered severely by ${ }^{178} \mathrm{Hf}^{2+}$. Therefore, the ${ }^{89} \mathrm{Y}^{+}$isotope was determined by eliminating its interference signal using the signals of ${ }^{86} \mathrm{Sr}$ (i.e. $\left.{ }^{86} \mathrm{Sr}_{\text {actual }}\right)$ with the following formulae: ${ }^{21}$

$$
\begin{gathered}
I^{88} \operatorname{Sr}_{\text {actual }}=I^{86} \operatorname{Sr}_{\text {actual }} * \frac{\mathrm{I}^{88} \mathrm{Sr}_{\text {abund }}}{\mathrm{A}^{86} \mathrm{Sr}_{\text {abund }}} \\
\mathrm{I}^{88} \mathrm{Sr}_{\text {interf }}=\mathrm{I}^{88} \mathrm{Sr}_{\text {found }}-\mathrm{I}^{88} \mathrm{Sr}_{\text {actual }} \\
\mathrm{I}^{89} \mathrm{Y}_{\text {interf }}=\mathrm{I}^{88} \mathrm{Sr}_{\text {interf }} * \frac{\mathrm{A}^{178} \mathrm{Hf}_{\text {abund }}}{\mathrm{A}^{176} \mathrm{Hf}_{\text {abund }}}
\end{gathered}
$$

(as ${ }^{176} \mathrm{Hf}^{2+} \&{ }^{178} \mathrm{Hf}^{2+}$ are interfering at ${ }^{88} \mathrm{Sr} \&{ }^{89} \mathrm{Y}$, respectively, and law of natural isotopes) ${ }^{21}$

$$
I^{89} Y_{\text {actual }}=I^{89} Y_{\text {found }}-I^{89} Y_{\text {interf }}
$$

where I ${ }^{86} \mathrm{Sr}_{\text {actual }}$ is the recorded signal intensity of ${ }^{86} \mathrm{Sr}, \mathrm{I}^{88} \mathrm{Sr}_{\text {actual }}$ is the actual (computed) signal intensity without interference and $\mathrm{A}$ ${ }^{88} \mathrm{Sr}_{\text {abund }}$ is the natural abundance of the ${ }^{88} \mathrm{Sr}$ isotope.

Validation of results. For comparison, the concentration of $\mathrm{Mg}$, $\mathrm{Al}, \mathrm{Cr}$ and $\mathrm{Fe}$ in $\mathrm{Hf}$ metal was also determined by ICP-OES (Table 4). It can be seen that the GD-QMS values of these elements, except for $\mathrm{Cr}$, are in good agreement with those obtained by ICP-

Table 4 Comparison of GD-QMS and ICP-OES Results $\left(\mu \mathrm{g} \mathrm{g}^{-1}, \mathrm{n}=4\right)$

\begin{tabular}{lcccc}
\hline Element & $\begin{array}{c}\text { ICP-OES } \\
( \pm \mathbf{S D})\end{array}$ & $\begin{array}{c}\mathbf{G D}-\mathbf{Q M S} \\
\mathbf{(} \mathbf{S D})\end{array}$ & $\mathbf{t}_{\text {calculated }}$ & $\mathbf{t}_{\text {critical }}(\mathbf{n}=\mathbf{4})$ \\
\hline $\mathbf{M g}$ & $12.1 \pm 1.7$ & $11 \pm 2$ & 0.73 & 2.78 \\
$\mathbf{A l}$ & $30 \pm 4$ & $32 \pm 3$ & 0.69 & 2.78 \\
$\mathbf{F e}$ & $19 \pm 3$ & $17 \pm 3$ & 0.81 & 2.78 \\
$\mathbf{C r}$ & $<10$ & $21 \pm 4^{\mathrm{a}}$ & - & 2.78 \\
$\mathbf{Z r}$ & $3936 \pm 157$ & $3950 \pm 40^{\mathrm{b}}$ & 0.15 & 2.78 \\
\hline
\end{tabular}

${ }^{\mathrm{a}}$ Interfered with ${ }^{40} \mathrm{Ar}^{12} \mathrm{C}^{+},{ }^{\mathrm{b}} \mathrm{XRF}$ value 
OES. In case of $\mathrm{Cr}$, the higher GD-QMS value is due to the isobaric interference from the polyatomic ion ${ }^{40} \mathrm{Ar}^{12} \mathrm{C}^{+}$. At this juncture, the tolerance level of $\mathrm{HF}$, due to its corrosiveness especially for the nebulizer and torch assembly, warrants discussion for the ICP-OES analysis. Hafnium forms a strong fluoro complex with $\mathrm{HF}$, and the concentration of $\mathrm{HF}$ remaining free after dissolution is calculated at $\sim 0.125 \%(\mathrm{v} / \mathrm{v})$. Even though the nebulizer of the instrument is HF resistant, $>0.1 \%(\mathrm{v} / \mathrm{v}) \mathrm{HF}$ might affect the quartz torch assembly and also the determination of the trace elements. To ascertain the influence of HF, which is present in slight excess of the tolerance level $(0.1 \mathrm{v} / \mathrm{v} \%)$, spike and recovery tests were carried out by adding $\mathrm{x} \%$ analyte to the $0.8 \mathrm{mg}$ $\mathrm{mL}^{-1} \mathrm{Hf}$ solution. The recoveries of all of the analytes are in the range of $95-100 \%$, which suggests the absence of any adverse effects of HF on the determination of the elements by ICP-OES. The data of the statistical analysis is also presented in Table 4. As the calculated values of $t$ were less than the critical $t$-value, it follows that there is no statistical difference between the results.

\section{CONCLUSIONS}

A GD-QMS method for the determination of impurities in Hf metal was successfully developed. The method involves use of a non-matrix matched standard, namely a Ni-based superalloy, and an internal standard element, $\mathrm{Zr}$, for the generation of the relative sensitivity factors (RSFs) of more than 70 elements for their quantification. The problem of a highly inhomogeneous distribution of $\mathrm{Hf}$ in the alloy standard has been solved for the direct use of the Ni superalloy standard for quantification. A consistent concentration value for the internal standard element $(\mathrm{Zr})$ in the Hf specimen was obtained using two independent techniques: ICP-OES and XRF. The true value of $\mathrm{Zr}$ has yielded the correct RSF value for the Hf matrix. A comparison of the results obtained with GD-QMS and ICP-OES shows good agreement between the methods. This validation revealed that the proposed approach using GD-QMS provides reliable results for the rapid determination of several impurities, such as metals as well as non-metals, in Hf and Hf-alloys.

\section{AUTHOR INFORMATION}

\section{Corresponding Author}

*R. Shekhar

Email address: shekhar671@rediffmail.com

\section{Notes}

The authors declare no competing financial interest.

\section{ACKNOWLEDGMENTS}

The authors thank Dr. A.K. Tyagi, Associate Director, Chemistry Group, BARC, for his continuous support and encouragement.

\section{REFERENCES}

1. D. E. Thomas and E. T. Hayes, A book on the Metallurgy of Hafnium. U.S. Atomic Energy Commission. Division of Reactor Development, 1960.

2. R. Tricot, J. Nucl. Mater., 1992, 189, 277-288.

3. M. L. Kotsar, S. A. Lavrikov, V. I. Nikaonov, A. V. Aleksandrov, S. G. Akhtonov and A.V. Alcksandrow, At. Energy, 2011, 111, 92-98.

4. O. Levy, G. L. W. Hart, S. Curtarolo, Acta Mater, 2010, 58, 28872897.

5. J. H. Choi, Y. Mao, J. P. Chang, Mater. Sci. Eng. R Rep., 2011, 72, 97-136.

6. L. Carpenter and R. W. Lewis, Analysis of High-purity Hafnium by Optical Emission Spectrography, United States Department of the Interior, Stewart L, Udall, Bureau of Mines, 1964.

7. X. R. Yang, Y. Liu, N. Li, M. W. Zang, Spectroscopy and Spectral Analysis, 2019, 39, 571-576.

8. C. Venzago, L. Ohanessian-Pierrard, M. Kasik, U. Collisi and S. Baude, J. Anal. At. Spectrom., 1998, 13, 189-193.

9. L. F. Vassmillet, J. Anal. At. Spectrom., 1989, 4, 451-455.

10. T. Takahashi and T. Shimamura, Anal. Chem., 1994, 66, 3274-3280.

11. D. M. Wayne, T. M. Yoshida, and D. E. Vance, J. Anal. At. Spectrom., 1996, 11, 861-869.

12. W. Vieth, and J. C. Huneke, Anal. Chem., 1992, 64, 2958-2964.

13. R. Qian, B. L. Siqin, S. J. Zhuo, R. X. Shen, C. Sheng and F. X. Gan, Chinese J. Anal. Chem., 2011, 5, 700-704.

14. W. Vieth, and J. C. Huneke, Spectrochim. Acta B, 1991, 46, 137-153.

15. J. S. Becker, H. J. Dietze, Inter. J. Mass Spectrom., 2003, 228, 127150.

16. F. L. King, J. Teng and R. E. Steiner, J. Mass Spectrom., 1995, 30, 1061-1075.

17. R. Shekhar, M. V. Balarama Krishna, J. Arunachalam, S. Gangadharan, At. Spectrosc., 1999, 20, 25-29.

18. M. V. B. Krishna, R. Shekhar, D. Karunasagar, J. Arunachalam, Anal. Chim. Acta, 2000, 408, 199-207.

19. R. Shekhar, J. Arunachalam, N. Das, A. M. S. Murthy, At. Spectrosc., 2004, 25, 203-210.

20. N. Jakubowski, D. Stuewer and W. Vieth, Fresen. J. Anal. Chem., 1988, 331, 145-149.

21. T. Takahashi, T. Shimamura, Anal. Chem., 1994, 66, 3274-3280. 